\title{
More than a flying syringe: Using functional traits in vector-borne disease research
}

Lauren J. Cator*1, Leah R. Johnson ${ }^{2}$, Erin A. Mordecai ${ }^{3}$, Fadoua El Moustaid ${ }^{4}$, Thomas R.C. Smallwood $^{1}$, Shannon L. LaDeau ${ }^{5}$, Michael A. Johansson ${ }^{6}$, Peter J. Hudson ${ }^{7}$, Michael Boots ${ }^{8}$, Matthew B. Thomas ${ }^{9}$, Alison G. Power ${ }^{10} \&$ Samraat Pawar $^{1}$

${ }^{1}$ Department of Life Sciences, Imperial College London, Silwood Park' Ascot, SL5 7PY, UK

${ }^{2}$ Department of Statistics, Virginia Polytechnic Institute and State University, Blacksburg, VA 24061, USA

${ }^{3}$ Department of Biology, Stanford University, Stanford, CA 94305, USA

${ }^{4}$ Department of Biological Sciences, Virginia Polytechnic Institute and State University, Blacksburg, VA 24061, USA

${ }^{5}$ The Cary Institute of Ecosystem Studies, Millbrook, NY 12545, USA

${ }^{6}$ CDC Dengue Branch and Harvard T.H. Chan School of Public Health, Boston, MA 02115, USA

${ }^{7}$ Huck Institutes of Life Sciences, Pennsylvania State University, University Park, PA 16802, USA

${ }^{8}$ Department of Integrative Biology, University of California Berkeley, Berkeley, CA 94720, USA

${ }^{9}$ Department of Entomology, Pennsylvania State University, University Park, PA 16802, USA

${ }^{10}$ Department of Ecology and Evolution, Cornell University, Ithaca, NY 14853, USA

*Corresponding Author: Department of Life Sciences, Imperial College London, Silwood Park Campus, Ascot SL57PY United Kingdom, Phone: 02075941785, 1.cator@imperial.ac.uk 


\section{Abstract}

2 Many important endemic and emerging diseases are vector-borne. The functional traits of vectors

3 affect not just pathogen transmission rates, but also the fitness and population dynamics of these

4 animals themselves. Increasing empirical evidence suggests that vector traits vary significantly at time

5 scales relevant to transmission dynamics. Currently, an understanding of how this variation in key

6 traits impacts transmission is hindered by a lack of both empirical data and theoretical methods for

7 mechanistically incorporating traits into transmission models. Here, we present a framework for

8 incorporating both intrinsic and environment-driven variation in vector traits into empirical and

9 theoretical vector-borne disease research. This framework mechanistically captures the effect of trait

10 variation on vector fitness, the correlation between vector traits, and how these together determine

11 transmission dynamics. We illustrate how trait-based vector-borne disease modelling can make novel

12 predictions, and identify key steps and challenges in the construction, empirical parameterisation and

13 validation of such models, as well as the organization and prioritization of data collection efforts.

14

15 Keywords: Vector-borne Disease Modelling, Traits, Population Dynamics, Transmission, Fitness,

16 Reproductive number

17 


\section{Contents}

28

I. Introduction

II. Trait Variation in Vectors

(1) Variation across the lifespan of an individual

(2) Variation within a population

(3) Environmentally driven variation

(4) Traits are mechanistically linked

III. Current approaches to incorporating trait variation into transmission dynamics

(1) Classical compartment models

(2) Adding in vector population dynamics

(3) Adding in trait variation

IV. A trait-based framework for VBD research

V. An example: A trait-based model of mosquito abundance and disease transmission

(1) The importance of trait sensitivity analyses

VI. A Traits-Based Framework Roadmap

(1) Trait $\rightarrow$ Parameter

a. A Worked Example: Deconstruction of Biting Rate

VII. Key Challenges

(2) Trait-Variation $\rightarrow$ Fitness

(3) Fitness $\rightarrow$ Population Dynamics

(1) Data

(2) Parameterisation

(3) Model Validation and Selection

52 VIII. Why now?

53 IX. Conclusion 


\section{INTRODUCTION}

Vector-borne diseases (VBDs) remain a serious threat to health and economic welfare

worldwide. At least one-third of the human population is thought to be impacted by mosquito-borne

diseases alone (WHO, 2018). Brazil loses an estimated 1.3 billion USD in productivity each year to

Chagas disease, which is transmitted by triatomine bugs (Lee et al., 2013). VBDs include re-emerging infections, such as dengue (San Martín et al., 2010; Dick et al., 2012), and new threats, such as Chikungunya, Zika, and Lyme disease (Mead, 2015; CDC, 2016; Faria et al., 2016). The impacts of VBDs are not only medical. Many important and emerging diseases of plants (e.g., Tomato yellow leaf curl virus, cassava mosaic virus, and citrus greening virus (Taylor et al., 2016)) and livestock (e.g., bluetongue (Wilson \& Mellor, 2009)) are transmitted by vectors. studies indicates that the behaviour and life history of vectors are key determinants of these VBD dynamics (reviewed below). The importance of vector abundance and life history in transmission dynamics is reflected by the fact that almost all VBD models incorporate vector biting rate, competence, adult survival, and density (Jeger et al., 2004; Reiner et al., 2013). These aspects of vector biology can be described as traits.

A trait is any measurable feature of an individual organism. Specifically, a trait is functional when it directly (e.g., mortality rate/probability) or indirectly (e.g., development time) determines individual fitness (McGill et al., 2006; Gibert et al., 2015) (henceforth we use "functional trait" and "trait" synonymously). In natural populations, trait variation between individuals, and within individuals over time is ubiquitous and has been shown to alter population and community level processes (Imura, Toquenaga, \& Fujii, 2003; McGill et al., 2006; Agashe, 2009; Gibert et al., 2015). It is widely accepted that vector traits are also important for transmission and they are likely to be temporally and spatially variable (Smith et al., 2014). While some models incorporate these traits, most do not accommodate trait variation. Mechanistically incorporating trait variation into transmission models should therefore improve the ability of models to predict transmission through time and space. 
84 similar time scales as pathogen transmission, or by directly changing transmission potential itself 85 (e.g., vector biting rate or competence). This is partly due to the fact, that the majority of animal and plant disease vectors are arthropods, and therefore have significantly shorter generation times (and thus, operate at faster timescales) than their host (May \& Anderson 1979). Furthermore, arthropods are small ectotherms, which means their abundances vary with fluctuations in environmental variables. Work from other fields indicates that both the mean and variation of a trait's distribution can have strong effects on the dynamics of populations (Norberg et al., 2001; Bolnick et al., 2011; Gibert et al., 2015). Trait variation has now begun to be identified as essential variables that are key for understanding the state and future trajectories of biodiversity and ecosystems (Kissling et al., 2018). Disease dynamics are strongly nonlinear, which means that variation in traits over time and across individuals can have compounding effects on transmission (Lloyd-Smith et al., 2005; Martin et al., 2019). Until we incorporate trait variation into VBD transmission models our ability to predict transmission dynamics at longer temporal and larger spatial scales will remain limited, like any ecological model that lacks a mechanistic basis (Getz et al., 2018). To incorporate trait variation robustly, the mechanistic links between biological parameters, and how their effects on vector population fitness can change population dynamics and transmission rates need to be considered.

There are two related challenges to understanding the parameter space in which trait variation could affect transmission. First, for most vector species, we lack basic data on traits underlying these parameters, and how they vary. Researchers are frequently forced to infer parameter values (for example, using the time it takes a mosquito to produce a clutch of eggs to infer biting rate) or use data

104 from related species to parameterise models (for example, Johnson et al. 2015, Mordecai et al. 2013). Second, while there are many statistical, correlative methods, we lack a theoretical framework to mechanistically incorporate parameter variation (through trait variation) into transmission models. Here, we propose a trait-based framework as the way forward on both empirical and theoretical fronts for making more accurate VBD transmission dynamic predictions. We begin by reviewing empirical evidence for trait variation in vectors and the degree which it has (or in some cases has not) been incorporated into previous transmission models. We then describe the trait-based 
modelling framework and provide an example of how this approach can produce novel predictions

112 and allows for investigation into the degree to which different traits drive transmission dynamics and

113 underlying fitness effects. Next we outline how this can be operationalized, both in terms of

114 incorporating traits into transmission models, and data collection efforts. Finally, we discuss further challenges in the way of implementing a trait-based approach in VBD research.

\section{TRAIT VARIATION IN VECTORS}

Variation in vector traits can be grouped into three primary types: 1) variation across the lifespan of an individual; 2) variation within a population; and 3) environmentally driven variation (Fig. 1)

\section{(1) Variation across the lifespan of an individual}

For transmission to occur a vector must survive the time it takes from acquiring the parasite to the parasite becoming infectious (extrinsic incubation period or EIP), which can be a large proportion of the vector life span. Therefore, older vector individuals are; 1) more likely to become infected because they are more likely to have been exposed, 2) more likely to be infectious because they are more likely to have survived EIP, and 3) are more likely to transmit the pathogen onwards because they are more likely to bite subsequent hosts after becoming infectious. Therefore, trait values at the end of life disproportionately contribute to transmission. Vector behaviour and life history may vary over the lifetime of an individual also due to intrinsic processes such as aging. There is evidence for age-specific vector competence (Soliman et al., 1993), immune function (Hillyer et al., 2005; Christensen et al., 2005; Laughton, Fan, \& Gerardo, 2014), flight performance (Nayar \& Sauerman, 1973) and feeding behaviour (Alto, Lounibos, \& Juliano, 2003; Den Otter, Tchicaya, \& Schutte, 2008; Bohbot et al., 2013). When multiple life stages of the vector are involved in transmission, transmission efficiency may vary with stage (Caraco et al., 2002; Coletta-Filho et al., 2014). All these time-dependent changes in vector traits could lead to significant variation in the number of infectious vectors and their contact rates with hosts. 


\section{0 (2) Variation within a population} and transmission potential. There are multiple examples of this kind of within-population variation in vectors. For example, the nutritional status of vectors can alter both their vector competence and several behavioural parameters linked to VBD transmission (Takken et al., 2013; Shapiro et al., 2016). Body size varies within populations (Renshaw, Service, \& Birley, 1994; De Xue, Edman, \& Scott, 1995; Kindlmann \& Dixon, 2003) and can drive significant variation in feeding, assimilation, and respiration, and therefore development and mortality rates (Brown et al., 2004; Savage, 2004; Amarasekare \& Savage, 2012). Inter-individual variation in age-specific mortality is important for transmission (Clements \& Paterson, 1981; Harrington et al., 2001, 2008; Styer et al., 2007). Recent evidence from several different systems shows that vectors infected with a variety of pathogens exhibit altered foraging behaviours (reviewed in (Murdock, Luckhart, \& Cator, 2017)). These types of variation between individuals in key traits such as biting rate, host preference, and longevity ultimately impact VBD pathogen transmission rate.

\section{(3) Environmentally driven variation}

The majority of vectors are small ectotherms, so their behaviour and life history are sensitive to 160 their environment. Variation due to environmental drivers, may have both short- or long-term effects on vector traits. At present most of the data on this kind of variation comes from investigations of temperature. Many studies have measured an effect of variation in environmental temperature on vector life history (Kersting, Satar, \& Uygun, 1999; Bayoh \& Lindsay, 2003; Delatte et al., 2009;

164 Ciota et al., 2014) and competence (Kramer, Hardy, \& Presser, 1983; Murral et al., 1996; Dohm,

165 O’Guinn, \& Turell, 2002; Paweska, Venter, \& Mellor, 2002; Wittmann, Mellor, \& Baylis, 2002).

166 Other environmental variables, such as humidity, can also directly affect vector life history (Wittmann 
et al., 2002; Costa et al., 2010).

(4) Traits are mechanistically linked

linked. For example, mosquitoes infected with bird malaria parasites exhibit reduced fecundity, which in turn increases longevity (Vézilier et al., 2012). These kinds of trait covariances, often appearing in

174 the form of life-history trade-offs (Charnov 1993), have implications for both vector population 175 fitness (and therefore abundance) and transmission rate. Therefore, any theoretical framework that incorporates vector traits and their variation must also account for the mechanistic relationships between traits. There is evidence that this type of incorporation of multiple, mechanistically-linked traits can yield new insights in transmission of VBDs as well as non-VBDs (Mordecai et al., 2013, 2017; Molnár et al., 2017). For example, recent work has incorporated metabolic traits into microand macro-parasite disease transmission (Molnár et al., 2017).

In summary, any theoretical framework for VBD should be able to capture changes in transmission dynamics emerging from trait variation (including for those not directly related to transmission), correlations between traits, and the resulting effects on vector population dynamics. We now consider past approaches towards incorporating traits into mathematical VBD models.

(1) Classical compartment models Infected, Recovered) sub-populations of the host and vector, often ignoring fluctuations in absolute abundances of the two species. For example, the Ross-Macdonald type model for malaria 
non-mosquito vectors) are based (MacDonald, 1957; May \& Anderson, 1979; Jeger et al., 2004;

196 Smith et al., 2012; Reiner et al., 2013) focuses exclusively on the parameters governing transmission

197 rate of the pathogen between susceptible and infected vector and host subpopulations, most of which

198 are mosquito traits. It yields a relatively simple equation for the basic reproduction number of the

199 disease $\left(R_{0}\right)$ - the number of new infectious cases that would arise from a single infectious case introduced into a fully susceptible host population — which quantifies its transmission potential or risk (MacDonald, 1957; Smith et al., 2012) (see SI section 2 for derivation):

202

$$
R_{0}=\left(\frac{V a^{2} b c \mathrm{e}^{-\mu P}}{H d \mu}\right)^{\frac{1}{2}}
$$

Here, $V$ is vector density, $a$ is per-vector biting rate, $b$ is the proportion of the bites by infective mosquitoes that produce infection in susceptible humans, $c$ is the proportion of bites by susceptible mosquitoes on infectious humans that infect mosquitoes (thus, $b c$ is vector competence), $\mu$ is adult vector mortality rate, $P$ is the extrinsic incubation period of the pathogen within the vector, $H$ is host density, and $d$ is the rate at which infected hosts recover and acquire immunity (Fig 2).

212 parameters used in this approach are all essentially traits that are either directly-measurable properties 213 of the vector itself $(a, \mu)$ or which can be derived from underlying traits of the vector and parasite $(b$,

$214 c, P$ ). However, in these models, it is assumed that vector (and host) traits do not affect total vector or 215 host population size and that these traits do not vary across individuals or over time (Fig. 1). 216 Furthermore, all of the vector's biology and ecology are represented by its adult (often female) biting rate, survival, extrinsic incubation period, competence, and abundance. All of these traits are assumed

218 to be independent of each other despite the fact that they are known to trade-off and feedback on each 219 other with potentially compounding effects on transmission. For example, biting rate $(a)$ is assumed to 220 have no effect on mortality $(\mu)$ or vector population density $(V)$ and does not vary across individuals 
or over time. All individual hosts and vectors are modelled as having an identical risk of infection that remains constant over time and vectors interact exclusively with the target host. This effectively reduces the vector to a homogeneous vehicle to transmit pathogens- a "flying syringe".

\section{(2) Compartment models with vector population dynamics}

226

Classical compartment models have been extended to incorporate vector population dynamics, by adding vector life-stage compartments (May \& Anderson, 1979; Anderson \& May, 1979; Hoshi, Higa, \& Chaves, 2014; Johnson et al., 2018; Ng et al., 2018) (Fig. 3). This introduces additional parameters for the vector's life history, all of which are directly measurable vector traits (also called demographic rates, e.g., mortality, fecundity), or parameters which can be derived from underlying traits (e.g. the transition probabilities $\left(p_{i}\right.$ 's) in Fig. 3 can be derived from stage-specific survivorship and development time). These models do relax the assumption that vector population dynamics are constant, but do not incorporate trait variation, mechanistic links between traits, or allow trait variation to drive vector population dynamics.

\section{(3) Adding in trait variation}

Subsequent studies have incorporated trait variation into the compartment as well as Anderson-May models (Fig. 4). Reiner et al (2013) found that while extensions of the RossMacDonald model to incorporate parasite latency in malaria vectors are commonplace, efforts to include variation in vector traits such as heterogeneity in host-vector contact or variation other vector (and host) attributes are rare. Several studies have shown that variation in single traits such as agespecific vector mortality drives changes in the predicted sensitivity of $R_{0}$ to vector control (Styer $e t$ al., 2007; Bellan, 2010; Novoseltsev et al., 2012). Incorporating variation in single life history traits associated with infection (McElhany, Real, \& Power, 1995; Koella, 2005; Lefèvre \& Thomas, 2008)

247 or nutrition (Shapiro et al., 2016) has also been found to affect key VBD parameters such as biting rate. In some cases, components of vector ecology have also been added to Ross-MacDonald type 
models, including environmental drivers (Beck-Johnson et al., 2013) or species interactions (Depinay et al., 2004; Nakazawa, Yamanaka, \& Urano, 2012). While these approaches incorporate trait variation, they don't necessarily link this to vector population dynamics or link between traits. infectious bites delivered by midges by combining the probability of survival through bluetongue virus EIP, age specific-biting rate, and mortality. They demonstrate that determining model parameters with traits can dramatically change the interpretation of $R_{0}$ as well as the estimated impact of vector control for bluetongue. However, while the traits drive a common transmission parameter, they are not mechanistically linked to one another. In a similar example, Brady et al. (2016) incorporated adult female mosquito blood feeding, egg laying, larval ecology and how these affect vectorial capacity. They found that this increased the relative importance of vector control methods relative to those that specifically targeted adults.

Most recently, trait variation has been incorporated directly into compartment models by incorporating environment driven trait variation. In this case multiple traits are determined by the same driver. For example, Parham \& Michael (2010) derived an equation for mean, asymptotic vector population size as a function of traits that are then allowed to be functions of environmental conditions. Mordecai et al. $(2013,2017)$ built upon this approach to include empirically derived unimodal thermal responses for life-history and transmission related traits. Brand et al. (2017) took a similar approach for allowing biting and EIP parameters to depend on temperature, but modelled the vector population using a statistical approach. All these studies have provided interesting insights into possible effects of trait variation, but they do not mechanistically link traits. We have not found examples of studies that have systematically incorporated trait variation, mechanistic linkages transmission dynamics. 
Here, we present a general trait-based research framework that unifies these previous approaches, and can provides a foundation for systematically tackling the challenge of incorporating trait variation into VBD dynamics. An overview of the framework is given in Fig. 5 (SI section 1, contains a more detailed framework description). In general, a fully trait-based VBD system's specification must include:

1. Transmission compartments for each focal host and vector species: For example, the SIR compartments as presented in the Ross-MacDonald type models (e.g., $H_{\mathrm{S}}, H_{\mathrm{R}}$ ) and may have additional host sub-compartments $\left(H_{j}\right.$, where $\left.j \geq 0\right)$ tailored to a particular disease.

2. Vector life history compartments: These would include the commonly used infected susceptible vector sub populations $\left(V_{\mathrm{S}}, V_{\mathrm{I}}\right)$, but additionally include the vectors' juvenile life stage subpopulations, starting at birth $\left(V_{0}\right)$ and followed by immature stages $\left(V_{l}\right.$, where $\left.l>0\right)$. In adult stages, we include the potential for additional stages $\left(V_{\mathrm{k}}\right)$ leading to infectious adults $\left(V_{\mathrm{I}}\right)$.

3. Species interaction compartments: These will depend on the VBD system, but typically at least one consumer-resource interaction would be necessarily incorporated, because all vectors experience significant mortality from predation at one or more life stages. This would require compartments for a resource species consumed by the vector $\left(R_{1}\right)$ and predator species that consume the vector $\left(C_{1}\right)$. In more complex systems, additional consumer and resource compartments $\left(C_{n}, R_{\mathrm{m}}\right)$ could be added.

4. Trait Variation: A suite of trait (e.g., vector mortality, fecundity and biting rates) to parameter mappings that determine fitness effects, and at least a single type of trait variation, such as with an environmental factor (dz/dE; e.g., temperature) (Fig. 1, 5). As we explain earlier, under this framework "fitness" has a more general meaning in its evolutionary connotation: it is the change in abundance value of any compartment (population) between time steps or spatial locations. Finally, note that a fitness effect in the transmission component (Fig. 5) changes abundances of the host's infected sub-population through changes in transmission rate (e.g., through biting rate) and reflects a change in fitness of the pathogen's (population) fitness. While many features of individuals and populations are measureable and may be variable, this framework specifies that 
these features are only important for transmission when they affect demographic, interaction, or transmission rates that drive population and transmission dynamics. We incorporate three key classes of functional traits; life history, interaction, and transmission traits (Table 1).

5. Mechanistic Links Between Traits: Traits should be mechanistically linked. This may be accomplished by explicitly modelling how multiple traits together affect a fitness parameter through shared bio-mechanical and metabolic constraints (see Section VI.1.a).

We do not show explicit linkages between trait variation, consumer-resource, and life history sub-compartments in Fig. 5 because these will vary with VBD system. For example, in the case of most aphid-transmitted diseases, the resource $(R)$ and host $(H)$ are often the same. For other vectors, such as Anopheles mosquitoes, the transmission relevant hosts $(H)$ may make up only a proportion of the resources $(R)$ that regulate growth and reproduction (e.g. (LoGiudice et al., 2003; Donnelly et al., 2015)).

We now illustrate how a trait-based approach (Fig. 5) can lead to novel predictions about transmission as an example. Temperature is a major source of environment-driven trait variation (Fig. 2), and affects variation in both adult and juvenile traits in vectors. To incorporate trait variation into transmission, we model the effects of temperature-driven life-stage specific trait variation on vector population density, $V$, through the population's intrinsic growth rate, $r_{\mathrm{m}}$. Full details of this worked example and the model are provided in SI section 3. Briefly, $r_{\mathrm{m}}$ is a function of adult peak fecundity and juvenile mortality $\left(\mu_{\mathrm{J}}\right)$. Variation in each of these traits across temperature is characterized by the thermal performance curve of each trait. By incorporating such environment-driven trait variation into a vector population abundance model we can derive the transmission dynamics over time (Fig. 6). 

previous studies (Hoshi et al., 2014; Johnson et al., 2018; Ng et al., 2018), where abundance (V) is directly associated with temperature by fitting a time-series model or where abundance is assumed, a priori, to follow a sinusoidal function (Bacaër \& Guernaoui, 2006; Bacaër 2007; Bacaër \& Ouifki, variation (Fig. 6), potentially with a time-lag. This result contrasts strongly with that from the traitbased approach that maps traits through parameters to vector population size. Specifically, we observe key differences in predictions of both abundance dynamics and the knock-on effects on transmission:

340 the trait-based model predicts that vector populations will emerge earlier in the year and persist later 341 into the cooler late summer season with a dip in the warmest period of the summer. These differences in $V$ feed through to a longer period of annual transmission with an early and late summer peak. The trait-based model predicts a longer transmission season than the phenomenological model, and reveals a decrease in transmission risk in the warmest period. The latter result in particular is surprising given the general "warmer is better" view, but is consistent with the results of Mordecai et al (2013) which incorporated variation (SI section 2.2). Interestingly, when metabolic theory was used to mechanistically model of infection of an endothermic host with an arctic nematode parasite, the continuous spring-to-fall transmission season morphed into two distinct transmission seasons as climate warmed was also observed (Molnár, 2013). The similarity in predicted transmission dynamics across these two very different systems suggests that mechanistically incorporating trait variation can reveal general constraints on VBD systems - in this case, the effect of temperature on VBD

352 dynamics through life-history traits. Additionally, a trait-based approach enables us to determine which traits matter the most for determining thermal sensitivity of transmission dynamics (through trait sensitivity analyses; see next section).

The example we have developed here also illustrates a key theoretical point we raised at the start. If vector traits (eqn 1; assumption 2) change at the same or shorter timescales (here, driven by within-year temperature change) than the rate of pathogen transmission, the classical approach will fail to capture important aspects of contemporary transmission dynamics (Anderson \& May, 1981; 
population assumption of classical transmission models has been to build phenomenological models for time varying vector populations, for example by assuming that the vector population oscillates sinusoidally (Heesterbeek \& Roberts, 1995; Bacaër, 2007). Although this approach is relatively simple, it cannot quantify or predict how variation in key vector traits or parameters (e.g., $a, b, c, \mu)$ interact to drive transmission dynamics over time if the relationship between abundance and temperature is non-linear. A trait-based approach provides new mechanistic insights and hypotheses, and predicts non-trivial dynamics that would likely inform public health and control decisions.

(1) The importance of trait sensitivity analyses

369

In addition to producing novel predictions, a trait-based approach allows investigation of the degree to which different traits drive transmission dynamics and underlying fitness effects. For example, a local trait sensitivity analysis of the population fitness component of the above trait-based model allows us to investigate the relative importance of juvenile versus adult traits in determining effects of temperature on abundance (and therefore transmission) (Fig. 7).

This leads to a key insight: juvenile traits are expected to play a major role in determining vector fitness across temperatures, and therefore abundance, and ultimately transmission. In particular, the trait sensitivity analysis adds further insight to why the trait-based approach yields very different predictions for population abundance and $R_{0}$ compared to a phenomenological approach. The thermal sensitivity of abundance $(V)$ and the underlying population fitness $\left(r_{m}\right)$ is driven by the variation of temperature-driven variation in larval stage traits. These predictions and insights provide quantitative targets for validation using field data. Sensitivity analyses of transmission measures with the contributions of traits to VBD system dynamics. 
Our relatively simple worked example in the previous section gives an idea of the steps one would need to take in order to use a trait-based approach. A full trait-based study would involve making the following links:

393 Research programs may focus on all or a portion of the following four sequential components or 394 steps. In our worked example, we only attempt to tackle step 2 and 3. Each step requires a relationship or mapping $(\rightarrow)$ to be quantified through empirical studies coupled with mathematical modelling. To be clear, useful progress and insights can be gained at each step. We now explain each of these steps, followed by an example.

\section{(1) Trait $\rightarrow$ Parameter}

A key component of any trait-based framework is the mapping of trait values onto mathematical VBD model parameters (Fig. 5). In this framework a parameter represents a process that would have a fitness effect within the model (e.g., it can change the abundance of one of the model compartments). For example, mortality rate decreases population abundance $\left(V_{\mathrm{S}}\right)$ and fecundity increases abundance $\left(V_{\mathrm{S}}\right)$. The trait/parameter delineation is not exclusive. Mortality rate and fecundity could also be interpreted as traits because they are directly measurable. In contrast, vectorial capacity is not a trait as it is a derived measure and cannot be directly measured. The distinction between "trait" and "parameter" is a matter of context; when a quantity is being used to drive another parameter it is a trait and when is directly affecting fitness it is a parameter. Deconstruction of parameters into their underlying traits bounds the parameter's feasible range (parameter space), and also reveals how different parameters are linked, and therefore interact or trade-off with one another to impact compartment fitness (Charnov, 1993) and ultimately, transmission dynamics. 
414 Savage, 2012; Pawar, Dell, \& Savage, 2015a). These approaches use a common currency (energy) to

415 map parameters onto traits. This inevitably establishes mechanistic links between traits. For example,

416 body size drives not just adult vector biting rate, but also its fecundity and mortality rates. Recent

417 advances in metabolic modelling offer an opportunity to determine encounter rate parameters between

418 vectors and hosts (Dell, Pawar, \& Savage, 2011; Pawar, Dell, \& Savage, 2012; Dell, Pawar, \&

419 Savage, 2014; Gilbert et al., 2014; Pawar et al., 2015a; Rizzuto, Carbone, \& Pawar, 2018) (see

example below) and even capture within-host parasite dynamics (Kirk et al., 2018). Empirical studies that validate trait-fitness models for specific vectors and VBD systems are of equal importance.

422 Ideally, such studies should measure multiple traits within individuals (for example, vector competence, fecundity, and survival) and how they relate to individual fitness (Ohm et al., 2016).

(a) A Worked Example: Deconstruction of Biting Rate

To illustrate Trait $\rightarrow$ Parameter mapping, we use recent advances in mechanistic, metabolic trait-based theory for species interactions (Pawar et al., 2012; Gibert et al., 2015; Pawar et al., 2015a) to develop a mathematical model that deconstructs biting rate (a parameter in the model) into its underlying functional traits and show how it is ultimately linked to the vector's adult body size. Heterogeneity in biting behaviour is considered important for determining transmission dynamics (Dye \& Hasibeder, 1986; Smith et al., 2014). This key transmission parameter in all VBD systems, that also underpins vector fitness, can be derived from body size (a physical trait) (Fig. 8, SI section 1.2)(De Leo \& Dobson, 1996). Adult vector size is a key physical trait as it determines many functional traits, and also itself responds strongly and predictably to external factors such as environmental temperature and resource availability (e.g., larval nutrition). 


$$
a=2 v_{r} d f(.) H
$$

443 Here, $a$ is biting rate (bites $\times$ time $^{-1}$ ) for a given host density $H$ (individuals $\times \operatorname{area}^{-1}$ ), $v_{\mathrm{r}}$ is relative

444 velocity between the vector and host, $d$ is the reaction distance (minimum distance at which the vector

445 detects and reacts to host), and $f($.$) is the host "risk" function that determines the (biting) functional$

446 response of the vector. That is, $f($.$) encapsulates the constraints on the vector's handling time (h) (the$

447 post-encounter phase in Fig. 8), which would be determined by its ability to land on and complete the

448 biting action successfully. Assuming each encounter between vector and host results in one bite, we 449 can derive biting rate as a function of body size (as physical trait) two key functional traits (vector's 450 flight velocity and reaction distance) (details in SI section 1.2):

$$
a=a_{0} m_{V}^{p_{v}+2 p_{d}} k^{p_{d}} f(.) H
$$

where $a_{0}$ is a normalization constant that also includes the effect of environmental temperature, $m_{\mathrm{V}}$ is the vector's body mass, $p_{\mathrm{v}}$ and $p_{\mathrm{d}}$ are scaling exponents for the size-dependence of vector flight velocity and reaction distance (respectively) $k$ is the vector-host body mass-ratio (a measure of their relative size difference). In the case where hosts are relatively rare, $f()=$.1 , but in the case where hosts are common (e.g., mosquito populations are often localized near human villages), it can be replaced with a more complex function that includes the effect of host handling time (physical limits on vector's biting \& ingestion rate; Fig. 2), which itself is likely to be vector size and temperature dependent (Dell et al., 2011; Pawar et al., 2012). flying vectors will have a lower mean or maximum biting rate relative to larger ones (e.g., midges vs. mosquitoes), that biting rates will be lower for walking vectors compared to flying ones (e.g., ticks vs. mosquitoes), and explains how temperature (through the scaling constants $a_{0}$ ) affects biting rate (e.g.,

465 (Dell et al., 2011; Mordecai et al., 2013; Dell et al., 2014), providing a mechanistic basis for 
467 Trait $\rightarrow$ Parameter mapping approach can be modified to accommodate vectors with different moving

468 or sensory modes (e.g., ticks vs. mosquitoes), and for the same host density (say, humans).

\section{(2) Trait-Variation $\rightarrow$ Fitness}

471

472

A population's fitness is essentially a distribution of fitness values across its individuals.

473 Therefore, the second key step in a trait-based VBD framework is to use Trait-Parameter mappings to

474 quantify how variation in functional traits generates variation in vector fitness and transmission. That

475 is, after identifying key functional traits and building trait-parameter models, the effect of trait

476 variation on the parameter, and eventually, fitness distribution in each class of compartment needs to

477 be quantified. The same trait can affect the fitness of more than one compartment. For example,

478 variation in biting rate or intrinsic mortality would affect both vector population fitness (e.g., $\left.r_{\max }\right)$ and transmission fitness (e.g., $R_{0}$ ). Incorporating or mapping any of the above three types of trait variation

480 (Fig. 1) onto vector population or transmission parameter requires the re-definition of the parameters 481 as functions (e.g., $p(z), d z / d t, d z / d E$; Fig. 3), which are better constructed mechanistically using Trait482 Parameter mappings. In our worked example, we explicitly derive population fitness using environment-driven traits.

\section{(3) Fitness $\rightarrow$ Population Dynamics}

The third step is to quantify how trait variation determines vector population abundance or dynamics over time through effects on fitness. This requires the construction of stage-structured population dynamic models (Fig. 5). There are two key challenges here. The first is quantification of the impact of trait variation (Fig. 3) on the vector's stage-structured population dynamics. One approach for doing so is trait-driver theory, which provides methods inherited from quantitative genetics to study how trait variation drives abundance dynamics (Norberg et al., 2001; Webb et al.,

493 2010; Enquist et al., 2015). This challenge may be made more difficult because most vectors have

494 stage-structured life cycles underlying population dynamics, which may have transgenerational effects 
(e.g., maternal effects) or carryover effects across life stages (Lorenz \& Koella, 2011). Initial progress can be made by simply measuring trait variation and "plugging" it into population dynamics models assumptions (for example see (Brand et al., 2016)) to determine how sensitive abundance is to trait one type of trait variation (environment-driven, specifically temperature). Because body-size is a key physical trait that also changes with life stage (over time), integral projection models may be another way to incorporate traits into VBDs (Coulson, 2012; Rees, Childs, \& Ellner, 2014; Metcalf et al., 2016).

There is increasing interest in incorporating species interactions into VBD transmission dynamics (vector-resource or vector-host interaction), and mortality with the vector's consumers (vector-

514 idealized life history parameter (e.g., development rate, fecundity, and mortality) functions to include

515 losses or gains due to species interactions. This approach could circumvent the additional complexity

516 of explicitly adding consumer-resource dynamics to vector population and transmission dynamics.

\section{8 (4) Population Dynamics $\rightarrow$ Transmission Dynamics}

The final step is to quantify transmission dynamics using trait-based vector population dynamics and resulting vector-host interaction rates (Fig. 5). To achieve this, two key challenges on

522 the theoretical front need to be tackled. First, how trait variation determines the timescale of 
523 fluctuations in vector population sizes and vector-host interaction traits relative to the timescale of

524 transmission dynamics needs to be modeled and validated. The trait-based approach, by deriving the

525 timescales of population fluctuations mechanistically, would "naturally" determine whether and when

526 the separation of the timescales of population and transmission dynamics, implicit in classical

527 (compartment-type) VBD models, is valid (see example below). Second, the appropriate level of

528 biological complexity (essentially, number of parameters or traits) needed to capture the effect of trait

529 variation through population dynamics on transmission dynamics needs to be determined. For

530 example, trait variation in both juveniles and adults may need to be incorporated simultaneously into

531 transmission models (Fig 7). In addition to vector traits that affect its population dynamics, models

532 and data on traits that determine the ability of the vector to transmit a pathogen (e.g., $P$ and $b c$ in eqn.

533 1) and interact with the host (e.g., $a$ in eqn. 1) will be needed. In many cases, these transmission-

534 relevant traits will be the same as those determining fitness. For example, both, encounter rate with

535 host and with the vector's resources (or predators) are determined by body size and velocity (Fig. 8).

536 Indeed, the host is the primary or sole resource in many vectors (e.g., aphids) which links

537 transmission parameters directly to the vector's fitness though biting and feeding rate.

538

539

540

541

542

543

544

545

546

547

548

549

550

\section{KEY CHALLENGES}

The four components for building trait-based models that we have outlined above will each

face four challenges to differing degrees; data: how to prioritize experiments and report data; parameterisation: how to link model components to empirical data; validation: how to test the trait fitness, trait variation - fitness, population dynamics, and transmission models; selection: how to pick the most parsimonious model.

\section{(1) Data}

Experiments to quantify vector traits involve taking individual measures on small insects that are often logistically difficult to work with due to ethical and biosafety concerns. As we have 
551 described above, theoretical work can help to prioritize which traits we should expect to have the

552 greatest impact on fitness and transmission. New data collection efforts are currently underway in

553 several disease systems, but the limited accessibility of data that have already been collected is a

554 major issue that needs to be addressed. It is critical to get as much information as possible from these

555 time- and labor-intensive experiments by reporting data at the most disaggregated level possible.

556 Many studies report point estimates of trait means/demographic rates across populations, across

557 lifespans, and over environmental gradients rather than presenting distributions or individual values.

558 Individual-level data are critical for accurately estimating within-population variation in trait values.

559 Beyond individual studies, consolidating datasets with individual measurements into common formats

560 would allow for the identification of gaps and coordinated data collection efforts to specifically target

561 the traits and conditions that are data-poor. We have recently launched a hub for storing and accessing vector trait data (www.vectorbyte.org) and a platform for coordinating data collection efforts

(www.vectorbite.org). Current data can be used to parameterise mechanistic models, including trait

distributions that accurately represent uncertainty and variation within populations. This would allow us to identify which traits and types of variation in these traits are not well characterized and may play an important role in transmission.

567

\section{(2) Parameterisation}

Accurately quantifying the distribution of trait values within populations is a major barrier to developing and refining Trait $\rightarrow$ Parameter and Trait Variation $\rightarrow$ Population Fitness models. First, better identification of how individual measurements link to modeled quantities needs to be more consistently addressed. For example, many models assume a single fixed value of the extrinsic incubation period (EIP - the time it takes for an exposed vector to become infectious). However, studies may report any number of variations in EIP - such as EIP $_{50}$ (time to $50 \%$ of vectors being infectious) of $\mathrm{EIP}_{90}$ (time to $90 \%$ infectious) (Ohm et al., 2018). Correctly identifying and

577 incorporating empirical measurements from the literature to match with the meaning of the trait or 578 parameters or transformations is necessary. Then the variation and uncertainty in the traits must be 
579 quantified. This involves the use of statistical methods for separating true biological variation from

580 measurement error, and thereby quantifying uncertainty in estimates of trait values (e.g., the mean or

581 variance of a trait). Using sophisticated approaches that allow quantification and propagation of uncertainty (e.g., from Trait $\rightarrow$ Parameter to population dynamics modelling), such as Bayesian inference, with or without prior information, will be key here (Clark, 2007; Johnson et al., 2015). In addition, parameter sensitivity analyses in trait-based models (Fig. 7) are crucial, and can provide biological insights into the traits driving variation in transmission (Johnson et al., 2015).

(3) Model Validation and Selection

A fundamental goal of trait-based VBD research should be to determine the conditions under which vector traits drive significant variation in realized transmission rate. This requires validation of models at each level or compartment of the framework (ideally) with data on the spatial or temporal distribution of traits/drivers as predictors. In contrast to inference or calibration of a model, validation is the process of assessing how well a parameterised model can replicate data that was not used for parameter inference/calibration (i.e., out-of-sample prediction) (Hooten \& Hobbs, 2015). For example, Trait $\rightarrow$ Parameter models need to be validated with data on population growth rates, the subsequent population dynamics models need to be validated with data on abundance variation over space or time, and the transmission models need to be validated using disease incidence data over space and time. However, when the data available for validation are very different in nature from the data used for model fitting or model outputs do not correspond to easily measured quantities, it can be difficult to determine when a model captures sufficient detail to adequately represent reality. Efforts to develop hierarchical model validation methods for the types of dynamic, trait-based models described here are ongoing (e.g., (LaDeau et al., 2011; Johnson, Pecquerie, \& Nisbet, 2013; Johnson et al., 2014; Sun, Lee, \& Hoeting, 2015). These will include Bayesian methods, which allow quantification of uncertainty and the incorporation of prior data (Clark, 2007; Hooten \& Hobbs,

605 2015). Not only do the statistical methods for (VBD) dynamical systems need to be refined, but as 606 they are developed it is important that these methods are made accessible for non-statisticians doing 
research in this area. This requires training a new generation of researchers in both the new modeling

608 techniques (so they can develop models that include details such as behaviour) as well as statistical

609 techniques appropriate for parameterizing and validating the models as they are developed.

610 It is inevitable and useful that multiple models will be built to address the same question

611 within any of the compartments of a trait-based framework (Johnson \& Omland, 2004). For example,

612 there are multiple ways to predict fitness from underlying life history traits (Amarasekare \& Coutinho,

613 2013). Comparing the predictions from multiple models allows us to identify which models are most

614 should make validation data sets publically available and accessible, and standardized metrics of

615 goodness-of-fit or similar should be reported for all models against validation sets. Second, publishing

616 the code used to generate model outputs as a standard practice would facilitate comparing

617 transmission models of all types - not just those incorporating trait variation. These steps would

618 enable model comparison and multi-model ensembles to be used for future predictions.

619

\section{WHY NOW?}

621

This is the ideal time to undertake the development of fully trait-based approaches in VBD

research. Recent public health crises have spurred government agencies to support the collection of now becoming available. At the same time, the movement towards reproducible research has resulted in open models and computational approaches that allow more direct comparison of models and easier expansion of existing methods.

At the same time, the broader field of trait-based research is maturing across ecological systems, with both the theory and experimental methods growing apace (McGill et al., 2006; Pawar, Woodward, \& Dell, 2015b). This provides VBD trait-based approaches with a solid foundation. There are many other areas of ecology that are currently striving to mechanistically incorporate trait 
634 developed for VBDs would have utility in solving problems in these other systems, such as predicting

635 changes in ecosystem services like primary production (Díaz et al., 2007; Blanchard et al., 2012).

Building a fully trait-based approach to modeling VBD dynamics is not the "quick and easy

637 path" (Kershner \& Lucas, 1980). It is data-hungry and requires extensive efforts to building models approaches) taking a more mechanistic approach, in general, provides a better way to extrapolate

641 dynamics across time or space (Bayarri et al., 2009). This kind of predictive power is becoming

642 increasingly critical as these pathogens continue to emerge and expand their ranges in the context of a

643 globalized and rapidly changing environment. Beyond that, incorporating traits with this bottom up

644 approach should allow us to better understand why we see the patterns of transmission that we do, and

645 potentially inform efforts at control. By explicitly modelling the fitness of a given trait and its effect

646 on population dynamics and fitness, trait-based approaches could be used to incorporate trait

647 evolution into transmission models. For instance, although we have focused on traits that directly

648 affect vector population fitness in idealized conditions, the addition of other traits that are mediated by

649 human intervention, such as insecticide resistance, is also possible within this framework. The

650 evolution of insecticide resistance is arguably the largest challenge to sustainable management of vector-borne diseases. A trait-based approach has the potential to better understand the implication of both current (e.g., chemical pesticides) and future control measures (e.g., genetically altered vectors) that inherently alter traits, while suggesting innovative and nuanced ways to apply control in a way

654 that to anticipates changes driven by the inherent complexities of these systems.

\section{CONCLUSION}

657

1. Mounting evidence shows that vector functional traits vary over lifespan, within populations, and across environmental gradients. This variation in key parameters is expected to alter disease transmission dynamics. 

developed the mathematical models and worked examples. transmission compartments.

\section{Acknowledgements}

2. Mathematical models of Vector-Borne Disease (VBD) dynamics to date have not mechanistically incorporated trait variation, and are therefore unable to capture changes in transmission dynamics that may emerge from different types and magnitudes of trait variation, the correlations between traits, and resulting vector population dynamics.

3. A fully trait-based VBD approach would involve explicitly modelling trait variation and its effect on transmission, vector life history, species interactions and also allowing feedback between traits. This requires mechanistic Trait-Parameter mapping, and the incorporation of trait variation (and co-variation) into the fitness of vector population and disease

4. Using a trait-based VBD approach can lead to novel predictions for transmission dynamics, and allows analyses of the relative importance of different traits in transmission dynamics. Incorporating trait variation into VBD transmission models will enhance our ability to predict transmission dynamics at longer temporal and larger spatial scales.

5. Increasing research efforts in the development of trait-based theory and data, combined with increasing investment in vector population surveillance makes this an ideal time for the community to systematically and strategically incorporate trait variation into VBD research.

We would like to thank the members of the VectorBiTE RCN (www.vectorbite.org) for their energy and stimulating discussions around these ideas. This work was funded by NIH grant 1R01AI12228401 and BBSRC grant BB/N013573/1 as part of the joint [NIH-NSF-USDA-BBSRC] Ecology and Evolution of Infectious Diseases program. EAM and LRJ were funded by NSF grant DEB-1518681. 
689

690

691

692

693

694

695

696

697

698

699

700

701

702

703

704

705

706

707

708

709

710

711

712

713

714

\section{References}

AgASHE, D. (2009) The stabilizing effect of intraspecific genetic variation on population dynamics in novel and ancestral habitats. American Naturalist 174, 255-267.

Alto, B.W., Lounibos, L.P. \& Juliano, S.A. (2003) Age-dependent bloodfeeding of Aedes aegypti and Aedes albopictus on artificial and living hosts. Journal of the American Mosquito Control Association 19, 347-352.

AMARASEKARE, P. \& SAVAGe, V. (2012) A framework for elucidating the temperature dependence of fitness. The American Naturalist 179, 178-191.

AMARASEKARE, P. \& COUTINHO, R.M. (2013) The intrinsic growth rate as a predictor of population viability under climate warming. Journal of Animal Ecology 82, 1240-1253.

Anderson, R.M. \& MAY, R.M. (1979) Population biology of infectious diseases: Part I. Nature 280, $361-367$.

ANDERSON, R.M. \& MAY, R.M. (1981) The population dynamics of microparasites and their invertebrate hosts. Philosophical Transactions of the Royal Society of London B 291, 451524.

BACAËR, N. (2007) Approximation of the basic reproduction number R0 for vector-borne diseases with a periodic vector population. Bulletin of Mathematical Biology 69, 1067-1091.

BACAËR, N. \& AIT DADS, E. (2012) On the biological interpretation of a definition for the parameter R0 in periodic population models. Journal of Mathematical Biology 65, 601-621.

BACAËR, N. \& GUERnAOUI, S. (2006) The epidemic threshold of vector-borne diseases with seasonality. Journal of Mathematical Biology 53, 421-436.

BACAËR, N. \& OUIFKI, R. (2007) Growth rate and basic reproduction number for population models with a simple periodic factor. Mathematical Biosciences 210, 647-658.

Bayarri, M., Calder, E., Lunagomez, S., Pitman, E., Berger, J., Dalbey, K., Patra, A., SPILLER, E. \& WOLPERT, R. (2009) Using statistical and computer models to quantify volcanic hazards. Technometrics 51, 401-413. 
715 BAYOH, M.N. \& LINDSAY, S.W. (2003) Effect of temperature on the development of the aquatic

716

717

718

719

720

721

722

723

724

725

726

727

728

729

730

731

732

733

734

735

736

737

738

739

740 stages of Anopheles gambiae sensu stricto (Diptera: Culicidae). Bulletin of Entomological Research 93, 375-381.

Beck-Johnson, L.M., Nelson, W.A., PaAijmans, K.P., Read, A.F., Thomas, M.B. \& BJørnstad, O.N. (2013) The effect of temperature on Anopheles mosquito population dynamics and the potential for malaria transmission. PLoS ONE 8, e79276.

BELLAN, S. (2010) The importance of age dependent mortality and the extrinsic incubation period in models of mosquito-borne disease transmission and control. PLoS One 5, e10165.

Blanchard, J.L., Jennings, S., Holmes, R., Harle, J., Merino, G., Allen, J.I., Holt, J., Dulvy, N.K. \& BARANGE, M. (2012) Potential consequences of climate change for primary production and fish production in large marine ecosystems. Philosophical Transactions of the Royal Society of London B 367, 2979-2989.

Bohbot, J., Durand, N., Vinyard, B. \& Dickens, J. (2013) Functional development of the octenol response in Aedes aegypti. Frontiers in Physiology.

Bolnick, D.I., Amarasekare, P., Araújo, M.S., BÜrger, R., Levine, J.M., NovaK, M., Rudolf, V.H.W., SChreIBer, S.J., URban, M.C. \& VASSEUR, D. (2011) Why intraspecific trait variation matters in community ecology. Trends in ecology \& evolution 26, 183-192.

Brady, O.J., Godfray, H.C.J., Tatem, A.J., Gething, P.W., Cohen, J.M., McKenzie, F.E., Perkins, T.A., Reiner, R.C., Tusting, L.S., SinKA, M.E., Moyes, C.L., EcKhoff, P.A., SCOTT, T.W., LINDSAY, S.W., HAY, S.I., ET AL. (2016) Vectorial capacity and vector control: reconsidering sensitivity to parameters for malaria elimination. Transactions of the Royal Society of Tropical Medicine and Hygiene 110, 107-117.

BRAnd, S., Rock, K. \& KeEling, M. (2016) The interaction between vector life history and short vector life in vector-borne disease control. PLoS computational biology 12, e1004837.

Brown, J.H., Gillooly, J.F., Allen, A.P., SAvage, V.M. \& West, G.B. (2004) Toward a metabolic theory of ecology. Ecology $\mathbf{8 5}, 1771-1789$. 
741 Caraco, T., Glavanakov, S., Chen, G., Flaherty, J.E., Ohsumi, T.K. \& Szymanski, B.K. (2002) Stage-structured infection transmission and a spatial epidemic: a model for Lyme disease. The American Naturalist 160, 348-359.

744 CDC (2016) Lyme disease: data and statistics. www.cdc.gov/lyme/stats/ [accessed 31 May 2016].

745 Charnov, E.L. (1993) Life History Invariants: Some Explorations of Symmetry in Evolutionary Ecology. Oxford University Press.

Christensen, B.M., LI, J., Chen, C.-C. \& NAPPI, A.J. (2005) Melanization immune responses in mosquito vectors. Trends in Parasitology 21, 192-199.

Ciota, A.T., Matacchiero, A.C., Kilpatrick, A.M. \& Kramer, L.D. (2014) The effect of temperature on life history traits of Culex mosquitoes. Journal of medical entomology $\mathbf{5 1}, 55$ 62.

Clark, J. (2007) Models for Ecological Data: An Introduction. Princeton University Press, Princeton N.J.

Clements, A.N. \& PAterson, G.D. (1981) The analysis of mortality and survival rates in wild populations of mosquitoes. Journal of Applied Ecology 18, 373-399.

COletta-Filho, H.D., DAUgherty, M.P., FerReira, C. \& LOPES, J.R. (2014) Temporal progression of Candidatus Liberibacter asiaticus infection in citrus and acquisition efficiency by Diaphorina citri. Phytopathology 104, 416-421.

Costa, E.A.P. DE A., SAntos, E.M. DE M., Correia, J.C. \& Albuquerque, C.M.R. DE (2010) Impact of small variations in temperature and humidity on the reproductive activity and

COULSON, T. (2012) Integral projections models, their construction and use in posing hypotheses in ecology. Oikos 121, 1337-1350. survival of Aedes aegypti (Diptera, Culicidae). Revista Brasileira de Entomologia 54, 488-

Crutsinger, G., Collins, M., Fordyce, J., Gompert, Z., Nice, C. \& SAnders, N. (2006) Plant genotypic diversity predicts community structure and governs an ecosystem process. Science 313, 966-968. 
768 De LeO, G.A. \& Dobson, A.P. (1996) Allometry and simple epidemic models for microparasites. Nature 379, 720-722.

De Xue, R., Edman, J.D. \& ScotT, T.W. (1995) Age and body size effects on blood meal size and multiple blood feeding by Aedes aegypti (Diptera: Culicidae). Journal of Medical Entomology 32, 471-474.

Delatte, H., Gimonneau, G., Triboire, A. \& Fontenille, D. (2009) Influence of temperature on immature development, survival, longevity, fecundity, and gonotrophic cycles of Aedes

Dell, A.I., PAwar, S. \& SAVAGe, V.M. (2011) Systematic variation in the temperature dependence of physiological and ecological traits. Proceedings of the National Academy of Sciences 108, $10591-10596$.

Dell, A.I., PAwar, S. \& SAVAge, V.M. (2014) Temperature dependence of trophic interactions are driven by asymmetry of species responses and foraging strategy. Journal of Animal Ecology 83, 70-84.

Den OtTer, C., TChicaya, T. \& SchutTe, M. (2008) Effect of age, sex and hunger on the antennal olfatory sensitivity of tsetse flies. Physiological Entomology 16, 173-182.

Depinay, J.M.O., Mbogo, C.M., Killeen, G., Knols, B., Beier, J., Carlson, J., Dushoff, J., BillingSley, P., Mwambi, H., GithuRe, J. \& OTHERS (2004) A simulation model of African

Díaz, S., Lavorel, S., De Bello, F., Quétier, F., Grigulis, K. \& Robson, T.M. (2007) Incorporating plant functional diversity effects in ecosystem service assessments. Proceedings of the National Academy of Sciences 104, 20684-20689.

Dick, O.B., San Martín, J.L., Montoya, R.H., Del Diego, J., Zambrano, B. \& Dayan, G.H. Medicine and Hygiene 87, 584-593. 
DohM, D.J., O'GuinN, M.L. \& TuRELl, M.J. (2002) Effect of environmental temperature on the ability of Culex pipiens (Diptera: Culicidae) to transmit West Nile Virus. Journal of Medical Entomology 39, 221-225.

Donnelly, B., BerRang-Ford, L., Ross, N.A. \& Michel, P. (2015) A systematic, realist review of zooprophylaxis for malaria control. Malaria Journal 14, 313.

800

Dye, C. \& Hasibeder, G. (1986) Population dynamics of mosquito-borne disease: effects of flies which bite some people more frequently than others. Transactions of the Royal Society of Tropical Medicine and Hygiene 80, 69-77.

804

805

806

Enquist, B.J., Norberg, J., Bonser, S.P., Violle, C., Webb, C.T., Henderson, A., SloAt, L.L. \&

Faria, N.R., Azevedo, R. Do S. Da S., Kraemer, M.U.G., SouZA, R., CunHa, M.S., Hill, S.C., SAVAGE, V.M. (2015) Scaling from traits to ecosystems: developing a general trait driver

Getz, W.M., Marshall, C.R., Carlson, C.J., Giuggioli, L., Ryan, S.J., Romañach, S.S., Boettiger, C., Chamberlain, S.D., Larsen, L., D’Odorico, P. \& O’Sullivan, D. (2018) Making ecological models adequate. Ecology Letters 21, 153-166.

Gibert, J.P., Dell, A.I., Delong, J.P. \& PAWar, S. (2015) Scaling-up trait variation from individuals to ecosystems. In Advances in Ecological Research (ed G.W. AND A.I.D.

817 Gilbert, B., Tunney, T.D., McCann, K.S., Delong, J.P., Vasseur, D.A., Savage, V., Shurin, J.B., Dell, A.I., BARTON, B.T. \& HARley, C.D. (2014) A bioenergetic framework for the temperature dependence of trophic interactions. Ecology Letters 17, 902-914.

Harrington, L.C., Buonaccorsi, J.P., Edman, J.D., Costero, A., Kittayapong, P., Clark, G.G. \& SCOTT, T.W. (2001) Analysis of survival of young and old Aedes aegypti (Diptera: Culicidae) from Puerto Rico and Thailand. Journal of medical entomology 38, 537-547. 
Harrington, L.C., Françoisevermeylen, null, Jones, J.J., Kitthawee, S., Sithiprasasna, R., EDMAn, J.D. \& ScotT, T.W. (2008) Age-dependent survival of the dengue vector Aedes aegypti (Diptera: Culicidae) demonstrated by simultaneous release-recapture of different age cohorts. Journal of Medical Entomology 45, 307-313.

HEESTERBEeK, J. \& RoberTs, M. (1995) Threshold quantities for infectious diseases in periodic environments. Journal of biological systems 3, 779-787.

Hillyer, J.F., Schmidt, S.L., Fuchs, J.F., Boyle, J.P. \& Christensen, B.M. (2005) Ageassociated mortality in immune challenged mosquitoes (Aedes aegypti) correlates with a decrease in haemocyte numbers. Cellular Microbiology 7, 39-51.

Hooten, M. \& HobBs, N. (2015) A guide to Bayesian model selection for ecologists. Ecological Monographs 85, 3-28.

Hoshi, T., HigA, Y. \& CHAVES, L.F. (2014) Uranotaenia novobscura ryukyuana (Diptera: Culicidae) population dynamics are denso-dependent and autonomous from weather fluctuations. Annals of the Entomological Society of America 107, 136-142.

ImURA, D., ToQuenaga, Y. \& FUJII, K. (2003) Genetic variation can promote system persistence in an experimental host-parasitoid system. Population Ecology 45, 205-212.

Jeger, M.J., Holt, J., Van Den Bosch, F. \& Madden, L.V. (2004) Epidemiology of insect-transmitted plant viruses: modelling disease dynamics and control interventions. Physiological Entomology 29, 291-304.

Johnson, J. \& OMLAND, K. (2004) Model selection in ecology and evolution. Trends in Ecology \& Evolution 19, 101-108.

844 Johnson, L., PECQUERIE, L. \& Nisbet, R. (2013) Bayesain inference for bioenergetic models. Ecology 94, 882-889. (2014) Mapping the distribution of malaria: current approaches and future directions. Pages 
851

852

853

854

855

856

857

858

859

860

861

862

863

864

865

866

867

868

869

870

871

872

873

874

875

876

Johnson, L.R., Ben-Horin, T., LAFFerty, K.D., McNally, A., MordeCAI, E., PAAIJMAns, K.P., PAWAR, S. \& RYAN, S.J. (2015) Understanding uncertainty in temperature effects on vectorborne disease: a Bayesian approach. Ecology 96, 203-213.

Johnson, L.R., Gramacy, R.B., Cohen, J., Mordecai, E., Murdock, C., Rohr, J., Ryan, S.J., Stewart-Ibarra, A.M. \& Weikel, D. (2018) Phenomenological forecasting of disease incidence using heteroskedastic Gaussian processes: A dengue case study. The Annals of Applied Statistics 12, 27-66.

Keesing, F., Belden, L.K., Daszak, P., Dobson, A., Harvell, C.D., Holt, R.D., Hudson, P., JOLLES, A., JONES, K.E. \& MiTCHELL, C.E. (2010) Impacts of biodiversity on the emergence and transmission of infectious diseases. Nature 468, 647.

Kershner, I. \& LuCAS, G. (1980) The Empire strikes back. Twentieth Century-Fox Film Corporation.

Kersting, U., SATAR, S. \& UyGUn, N. (1999) Effect of temperature on development rate and fecundity of apterous Aphis gossypii Glover (Hom., Aphididae) reared on Gossypium hirsutum L. Journal of Applied Entomology 123, 23-27.

KinDLMANN, P. \& DiXON, A.F.G. (2003) Insect predator-prey dynamics and the biological control of aphids by ladybirds. In First international symposium on biological control of arthropods. USDA Forest Service, USA pp. 118-124.

Kirk, D., Jones, N., Peacock, S., Phillips, J., Molnár, P.K., KrkošEK, M. \& LuiJCKX, P. (2018) Empirical evidence that metabolic theory describes the temperature dependency of withinhost parasite dynamics. PLOS Biology 16, e2004608.

Kissling, W.D., Walls, R., Bowser, A., Jones, M.O., Kattge, J., Agosti, D., Amengual, J., Basset, A., VAn Bodegom, P.M. \& CoRnelissen, J.H. (2018) Towards global data products of Essential Biodiversity Variables on species traits. Nature ecology \& evolution 2 , $1531-1540$.

KoELLA, J.C. (2005) Malaria as a manipulator. Behavioural processes 68, 271-273. 
877 KRAMER, L.D., HARDY, J.L. \& PRESSER, S.B. (1983) Effect of temperature of extrinsic incubation on the vector competence of Culex tarsalis for Western Equine Encephalomyelitis Virus. The American Journal of Tropical Medicine and Hygiene 32, 1130-1139.

880

LADEAU, S.L., Glass, G.E., HobBS, N.T., LATIMER, A. \& OSTFELD, R.S. (2011) Data-model fusion

881

882

883

884

885

886

887

888

889

890

891

892

893

894

895

896

897

898

899

900

901

902

903 to better understand emerging pathogens and improve infectious disease forecasting. Ecological Applications: A Publication of the Ecological Society of America 21, 1443-1460.

Laughton, A.M., FAn, M.H. \& GERARDO, N.M. (2014) The combined effects of bacterial symbionts and aging on life history traits in the pea aphid, Acyrthosiphon pisum. Applied and environmental microbiology 80, 470-477.

LLOYD-SMith, J.O., SCHREIBER, S.J., KoPP, P.E. \& GETZ, W.M. (2005) Superspreading and the effect of individual variation on disease emergence. Nature $\mathbf{4 3 8}, 355-359$.

LeE, B.Y., BAcon, K.M., BotTAZZI, M.E. \& HoteZ, P.J. (2013) Global economic burden of Chagas disease: a computational simulation model. The Lancet Infectious Diseases 13, 342-348.

LefÈVRe, T. \& ThOMAS, F. (2008) Behind the scene, something else is pulling the strings: emphasizing parasitic manipulation in vector-borne diseases. Infection, genetics and evolution 8, 504-519.

LlOYD-SMith, J.O., SchreIBER, S.J., KoPP, P.E. \& GETZ, W.M. (2005) Superspreading and the effect of individual variation on disease emergence. Nature 438, 355-359.

LoGiudice, K., OstFeld, R.S., SchmidT, K.A. \& KeEsing, F. (2003) The ecology of infectious disease: effects of host diversity and community composition on Lyme disease risk. Proceedings of the National Academy of Sciences 100, 567-571.

LOREnZ, L. \& KoElla, J. (2011) Maternal environment shapes the life history and susceptibility to malaria of Anopheles gambiae mosquitoes. Malaria Journal 10, 1-8.

MacDonalD, G. (1957) The epidemiology and control of malaria. Oxford University Press, London.

Martin, L.B., AdDison, B., Bean, A.G., Buchanan, K.L., Crino, O.L., EASTwood, J.R., Flies, A.S., HAmede, R., HiLl, G.E. \& KlaAsSen, M. (2019) Extreme Competence: Keystone Hosts of Infections. Trends in Ecology \& Evolution. 
MAY, R.M. \& ANDERSON, R.M. (1979) Population biology of infectious diseases: Part II. Nature 280, $455-461$.

MCElHany, P., REAL, L.A. \& PoweR, A.G. (1995) Vector preference and disease dynamics: a study of barley yellow dwarf virus. Ecology, 444-457.

MCGILL, B.J., ENQUist, B.J., WeIHER, E. \& WESTOBY, M. (2006) Rebuilding community ecology 909 from functional traits. Trends in Ecology \& Evolution 21, 178-185.

MEAD, P.S. (2015) Epidemiology of Lyme disease. Infectious Disease Clinics of North America 29, $187-210$.

MetCalf, C.J.E., Graham, A.L., MartineZ-BAKKeR, M. \& Childs, D.Z. (2016) Opportunities and challenges of Integral Projection Models for modelling host-parasite dynamics. Journal of Animal Ecology 85, 343-355.

MOLNÁR, P. (2013) Metabolic approaches to understanding climate change impacts on seasonal hostmacroparasite dynamics. Ecology Letters 16, 9-21.

Molnár, P.K., Sckrabulis, J.P., Altman, K.A. \& Raffel, T.R. (2017) Thermal performance curves and the metabolic theory of ecology — a practical guide to models and experiments for parasitologists. Journal of Parasitology 103, 423-439.

Mordecai, E.A., Cohen, J.M., Evans, M.V., GudaPati, P., Johnson, L.R., LiPPi, C.A., Miazgowicz, K., Murdock, C.C., Rohr, J.R., Ryan, S.J., SAvage, V., Shocket, M.S., Stewart Ibarra, A., Thomas, M.B. \& Weikel, D.P. (2017) Detecting the impact of temperature on transmission of Zika, dengue, and chikungunya using mechanistic models. PLoS neglected tropical diseases 11, e0005568.

Mordecai, E.A., PaAijmans, K.P., Johnson, L.R., Balzer, C., Ben-Horin, T., De Moor, E., McNally, A., Pawar, S., Ryan, S.J., Smith, T.C. \& LAFFerTy, K.D. (2013) Optimal Letters 16, 22-30. infected vectors. Current Opinion in Insect Science 20, 28-33. 
MurRal, D.J., Nault, L.R., Hoy, C.W., Madden, L.V. \& Miller, S.A. (1996) Effects of temperature and vector age on transmission of two Ohio strains of aster yellows phytoplasma by the aster leafhopper (Homoptera: Cicadellidae). Journal of Economic Entomology 89, $1223-1232$.

NAKAZAWA, T., YAMANAKA, T. \& URANO, S. (2012) Model analysis for plant disease dynamics comediated by herbivory and herbivore-borne phytopathogens. Biology Letters 8, 685-688.

NAYAR, J.K. \& SAUERMAN, D.M. (1973) A comparative study of flight performance and fuel utilization as a function of age in females of Florida mosquitoes. Journal of insect physiology 19, 1977-1988.

NG, K.C., Chaves, L.F., Tsai, K.H. \& ChUang, T.W. (2018) Increased adult Aedes aegypti and Culex quinquefasciatus (Diptera: Culicidae) abundance in a dengue transmission hotspot, compared to a coldspot, within Kaohsiung City, Taiwan. Insects 9, 1-16.

Norberg, J., Swaney, D.P., Dushoff, J., Lin, J., Casagrandi, R. \& Levin, S. (2001) Phenotyptic diversity and ecosystem functioning in chaning environments: a theoretical framework. PNAS 98, 11376-11381.

Novoseltsev, V.N., Michalski, A.I., Novoseltseva, J.A., Yashin, A.I., CAReY, J.R. \& Ellis, A.M. (2012) An age-structured extension to the vectorial capacity model. PLOS ONE 7, e39479.

OHM, J.R., BALdini, F., BARREAUX, P., LEFEVRE, T., LynCh, P.A., SuH, E., WhiteheAD, S.A. \& THOMAS, M.B. (2018) Rethinking the extrinsic incubation period of malaria parasites. Parasites \& Vectors 11, 178.

Ohm, J.R., Teeple, J., Nelson, W.A., Thomas, M.B., Read, A.F. \& CAtor, L.J. (2016) Fitness consequences of altered feeding behaviour in immune-challenged mosquitoes. Parasites \& Vectors $9,113$.

PARHAM, P.E. \& MichAEL, E. (2010) Modeling the effects of weather and climate change on malaria transmission. Environmental Health Perspectives 118, 620-626. 
Pawar, S., Dell, A.I. \& SaVage, V. (2015a) From Metabolic Constraints on Individuals to the Dynamics of Ecosystems. Aquatic Functional Biodiversity: An Ecological and Evolutionary Perspective, 3-36.

960

Pawar, S., Dell, A.I. \& SAVAge, V.M. (2012) Dimensionality of consumer search space drives 961 trophic interaction strengths. Nature $\mathbf{4 8 6}, 485$.

962

PAWAR, S., WoOdWARD, G. \& DELl, A. (2015b) Trait-Based Ecology-from structure to function, 1st edition. Elsevier Academic Press, Oxford, UK.

Paweska, J.T., Venter, G.J. \& Mellor, P.S. (2002) Vector competence of South African Culicoides species for bluetongue virus serotype 1 (BTV-1) with special reference to the effect of temperature on the rate of virus replication in C. imicola and C. bolitinos. Medical and Veterinary Entomology 16, 10-21.

Reiner, R.J., Perkins, T., Barker, C., Niu, T., Chaves, L., Ellis, A., George, D., Le Manach, A., Pulliam, J., Bisanzio, D., Buckee, C., Chiyaka, C., Cummings, D., Garcia, A., Gatton, M., ET AL. (2013) A systemic review of mathematical models of mosquito-bourne pathogen transmission: 1970:2010. J R Soc Interface 10, 20120921.

RENSHAW, M., SERVICE, M.W. \& BIRLEY, M.H. (1994) Size variation and reproductive success in the mosquito Aedes cantans. Medical and Veterinary Entomology 8, 179-186.

RizzUTO, M., CARBONE, C. \& PAWAR, S. (2018) Foraging constraints reverse the scaling of activity time in carnivores. Nature ecology \& evolution 2, 247.

Roux, O., Vantaux, A., Roche, B., Yameogo, K.B., Dabiré, K.R., Diabaté, A., Simard, F. \& LEFÈVRE, T. (2015) Evidence for carry-over effects of predator exposure on pathogen transmission potential. Proceedings of the Royal Society B 282, 20152430.

San Martín, J.L., Brathwaite, O., Zambrano, B., Solórzano, J.O., Bouckenooghe, A., 
983

984

985

986

987

988

989

990

991

992

993

994

995

996

997

998

999

1000

1001

1002

1003

1004

1005

1006

1007

1008

1009

SAVAGE, V.M. (2004) Improved approximations to scaling relationships for species, populations, and ecosystems across latitudinal and elevational gradients. Journal of Theoretical Biology 227, $525-534$.

Shapiro, L.L.M., Murdock, C.C., Jacobs, G.R., Thomas, R.J. \& ThOMAS, M.B. (2016) Larval food quantity affects the capacity of adult mosquitoes to transmit human malaria. Proceedings of the Royal Society B 283, 20160298.

Smith, D.L., BAtTle, K.E., Hay, S.I., BARKer, C.M., Scott, T.W. \& McKenZIE, F.E. (2012) Ross, Macdonald, and a theory for the dynamics and control of mosquito-transmitted pathogens. PLoS Pathog 8, e1002588.

Smith, D.L., Perkins, T.A., Reiner, R.C., BArker, C.M., Niu, T., Chaves, L.F., Ellis, A.M., George, D.B., Menach, A.L., Pulliam, J.R.C., Bisanzio, D., Buckee, C., ChiYaKa, C., Cummings, D.A.T., GARCIA, A.J., ET AL. (2014) Recasting the theory of mosquito-borne pathogen transmission dynamics and control. Transactions of The Royal Society of Tropical Medicine and Hygiene 108, 185-197.

Soliman, B., Abo Ghalia, A., Shoukry, A. \& Merdan, A. (1993) Mosquito age as a factor influencing the transmission of Wuchereria bancrofti. Journal of the Egyptian Society of Parasitology 23, 717-722.

StYeR, L.M., CAREY, J.R., WANG, J.-L. \& SCOTT, T.W. (2007) Mosquitoes do senesce: departure from the paradigm of constant mortality. The American Journal of Tropical Medicine and Hygiene 76, 111-117.

SUN, L., LEE, C. \& HOETING, J.A. (2015) Parameter inference and model selection in deterministic and stochastic models via approximate Bayesian computation: modelling a wildlife epidemic. Environmentrics 26, 451-462.

TaKken, W., Smallegange, R.C., Vigneau, A.J., Johnston, V., Brown, M., Mordue-Luntz, A. \& BillingSLEY, P.F. (2013) Larval nutrition differentially affects adult fitness and Plasmodium development in the malaria vectors Anopheles gambiae and Anopheles stephensi. Parasites \& Vectors 6, 345. 
1010 Taylor, R., Mordecai, E., Gilligan, C., Rohr, J. \& Johnson, L. (2016) Mathematical models are 1011 a powerful method to understand and control the spread of Huanglongbing. PeerJ 4, e2642.

1012 VÉZiLier, J., Nicot, A., GAndon, S. \& Rivero, A. (2012) Plasmodium infection decreases fecundity 1013 and increases survival of mosquitoes. Proceedings of the Royal Society B 279, 4033-4041.

1014 Webb, C.T., Hoeting, J.A., Ames, G.M., Pyne, M.I. \& LeRoy Poff, N. (2010) A structured and dynamic framework to advance traits-based theory and prediction in ecology. Ecology Letters 13, 267-283.

1017 WiLson, A.J. \& MELLOR, P.S. (2009) Bluetongue in Europe: past, present and future. Philosophical 1018 Transactions of the Royal Society B: Biological Sciences 364, 2669-2681.

1019 WitTManN, E.J., Mellor, P.S. \& BAYLIs, M. (2002) Effect of temperature on the transmission of orbiviruses by the biting midge, Culicoides sonorensis. Medical and Veterinary Entomology 16, 147-156.

WORLD HEALTH ORGANIZATION (2017) Vector-borne diseases factsheet. 


\section{FIGURE LEGENDS}

Figure 1. Types of trait variation found in all VBD systems. A: Across-individuals: for example,

variation in a trait $(z)$ within a population at a fixed point in time. The distribution $(\mathrm{p}(z)$ around the mean $(\bar{z})$, represents amount individual variation not measurement error. For example, we could measure the probability of biting of individuals in a population at a particular age (based on data reviewed in Murdock et al. 2017) . B: Within-individual, over time: for example, biting probability may vary over the vector's lifespan (based on data reviewed in Murdock et al. 2017). Such variation is quantifiable as a continuous time-dependent function $d z / d t$, where $d z$ is the (differential) change in trait variation change with time $(d t)$.

C: Environment-driven: For example, biting rate varies unimodally with temperature (based on Mordecai et al. 2013). Such variation is quantifiable as a continuous environment state-dependent function, $d z / d E$. D: Combined variation: The three types of trait variation may appear in combination. For example, across-individual trait variation may change over time. The upper line represents change in mean and variance of the trait, while the lower line represents change only in the mean. We use derivatives for quantifying over-time, with-environment and combined types of trait variation to represent the idealized scenario that the trait value function varies continuously and smoothly with respect to another variable. In reality, it may not always be possible to express these as smooth functions for empirical reasons.

Figure 2. Traits in classical compartment models. As an illustration, we show here a RossMacdonald type model for malaria transmission by a mosquito vector. Most of the vector parameters in this model $-a, b, c, P, \mu-$ are directly measurable vector traits $(a, \mu)$, or can be derived from underlying vector and parasite traits $(b, c, P)$. The corresponding equations and parameter definitions

1047 are shown in SI section 2. $H$ is the total host density which is made up of susceptible $\left(H_{S}\right)$, Infected $1048\left(H_{I}\right)$ and Recovered $\left(H_{S}\right)$ sub-groups. Total vector density $(V)$ is made up for Infected $\left(V_{I}\right)$, Exposed $\left(V_{E}\right)$ and Susceptible $\left(V_{S}\right)$ sub-groups. 
1053 Anderson-May framework includes the vector life-history compartments. As an illustration, we

1054 extend the classical Ross-MacDonald type models model for malaria (Fig. 2) to include mosquito life

1055 history. This introduces additional parameters (vector life stage-specific $\mu$ 's, fecundity $f$, and stage

1056 transition probabilities $p_{i}^{\prime} s$ ), all of which are directly measurable vector traits (the $\mu$ 's, $f$ ), or which

1057 can be derived from underlying traits (the $p_{i}{ }^{\prime} s$ ). The corresponding equations and parameter definitions are shown in SI section 2.

1059

1060 Figure 4. Trait variation in compartment models. In some cases traits and trait variation are used 1061 to drive specific components of the classic compartment model (Fig. 2) directly. In some cases traits 1062 are individually driven by a common driver (in most examples temperature). Traits are still not related to each other mechanistically, and do not drive the transmission process dynamically through changes in population abundances (e.g., as would happen in the Anderson-May model framework).

Figure 5. The trait-based framework for vector-borne disease systems. For illustration, we have used a mosquito-borne disease, but this framework can be applied to any VBD with distinct stage or age classes (further details in SI). Arrows between panels represent parameters (potentially with underlying traits) that determine population or transmission dynamics through (absolute) fitness effects. Transmission dynamics compartments: Number of Susceptible (S), Infected (I), and

1071 Recovered (R) hosts $\left(H_{\mathrm{S}}, H_{\mathrm{I}}, H_{\mathrm{R}}\right.$, respectively; additional compartments, $H_{j}$, can be added) and 1072 number of Susceptible, Infected, and Exposed (E) vectors ( $V_{\mathrm{S}}, V_{\mathrm{I}}, V_{\mathrm{E}}$ respectively). Vector population 1073 dynamics compartments: number of vector individuals at egg, larval pupal and adult stages $\left(V_{0}, V_{1}, V_{2}\right.$, $1074 V_{\mathrm{S}}$ respectively; additional compartments $V_{k}$ can be added); Species interaction compartments: 1075 Abundance of a single resource species $\left(R_{1}\right)$ that is the primary energy source of the vector population 1076 (may actually be the host itself, so $R_{l}=H_{\mathrm{S}}$ ), and a single consumer species $\left(C_{1}\right)$ that is the primary 1077 source of mortality for the vector population; Trait variation: A suite of trait to parameter mappings 1078 that determine fitness (e.g., vector mortality, fecundity and biting rates), and a single type of trait 1079 variation, such as variation with an environmental factor (dz/dE; e.g., temperature; see Fig. 3). For 
1080

1081

1082

1083

1084

1085

1086

1087

1088

1089

1090

1091

1092

1093

1094

1095

1096

1097

1098

1099

1100

1101

1102

1103

1104

1105

1106

developing a mathematical model of such a system, the most common tool would be ordinary differential equation (ODE) systems, as illustrated in SI Section 1.

Figure 6. An example trait-based model for malaria transmission. We illustrate here the contrast in models and resulting dynamics produced from phenomenological vs. trait-based approaches. Both models cover a time scale of one year and seek to predict the fluctuation in transmission risk or rate $\left(R_{0}\right)$ during that period. Full details of both models can be found in SI section 3.

Figure 7. An example trait sensitivity analysis. Analyzing the influence of individual fitness traits on the thermal sensitivity of population fitness of mosquito vectors reveals that juvenile traits have a stronger influence than adult traits in shaping population fitness $\left(r_{m}\right)$ across temperatures- $\left(b_{\mathrm{pk}}\right)$, agerelated fecundity decline rate $(\kappa)$, adult mortality rate $(\mu)$ and juvenile development time $(\alpha)$ and juvenile mortality $\left(\mu_{\mathrm{J}}\right)$. The vertical dashed line marks the thermal optimum of fitness. The sensitivity of $r_{m}$ to the thermal dependence can be assessed by deviation of $d r_{m} / d T$ from zero. When $d r_{m} / d T$ is positive this means that population fitness increases at this temperature. A. The sensitivity of $r_{m}$ to the thermal dependence of each parameter can be assessed by deviation of each evaluated partial derivative with respect to each parameter (the differently coloured lines) from zero and compared to the full model (black). B. Traits can be combined by life stage, with development rate and juvenile mortality categorised as juvenile traits and adult mortality, fecundity, and rate of loss of fecundity as adult traits. This reveals the relative contribution of the thermal performance curve of each life stage to the thermal performance curve of $r_{m}$, again with greater deviation from zero indicating a greater contribution. Full details of the trait sensitivity analysis are in SI Section 4.

Figure 8. Illustration of a Trait-Parameter mapping. We develop a mechanistic, trait-based model for biting rate (a key transmission parameter; eqn. 1) of vectors by deconstructing it into component functional traits (shown above). Biting rate $(a)$ can be decomposed into relative velocity $\left(v_{r}\right)$, distance between vectors and hosts $(d)$, risk $(f()$.$) and host density (H)$. These parameters can be further 
1107 decomposed so that $\mathrm{f}($.$) is determined by handling time (h)$ and the mass-specific velocities of the

1108 vector and host $\left(V_{V}, V_{R}\right)$ as in eq. 2. The model derivation is in SI section 1.2. 


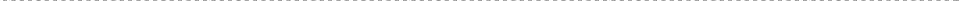




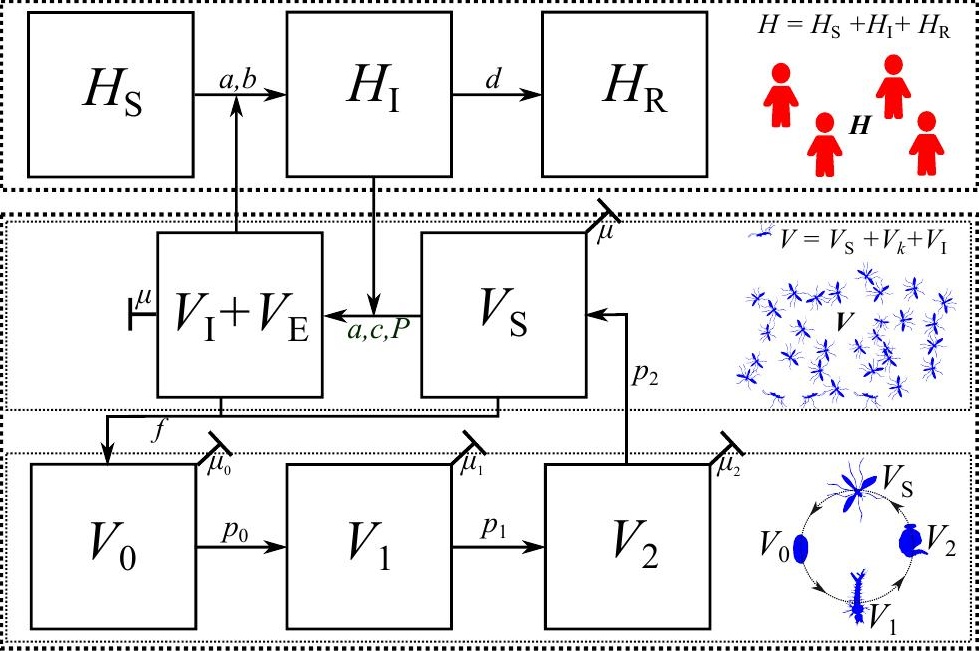



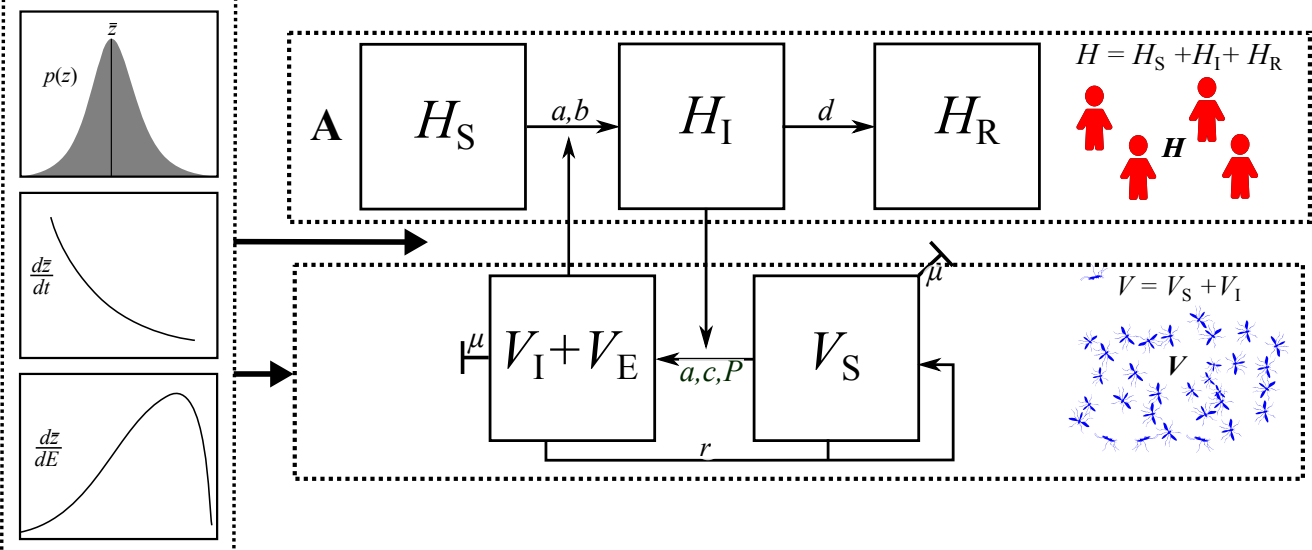
Temperature variation

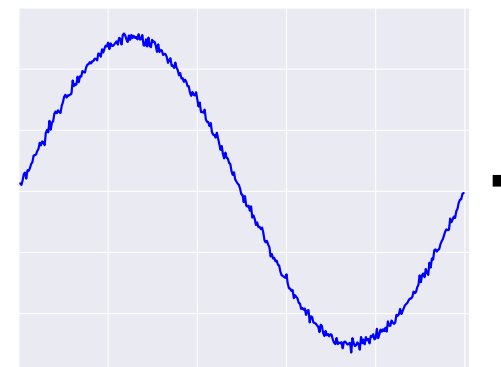

Time

$\downarrow$

Phenomenological

Abundance

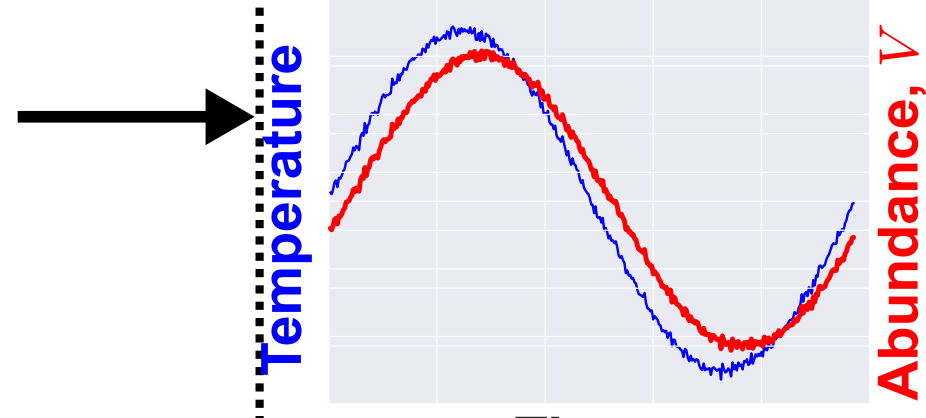

Time

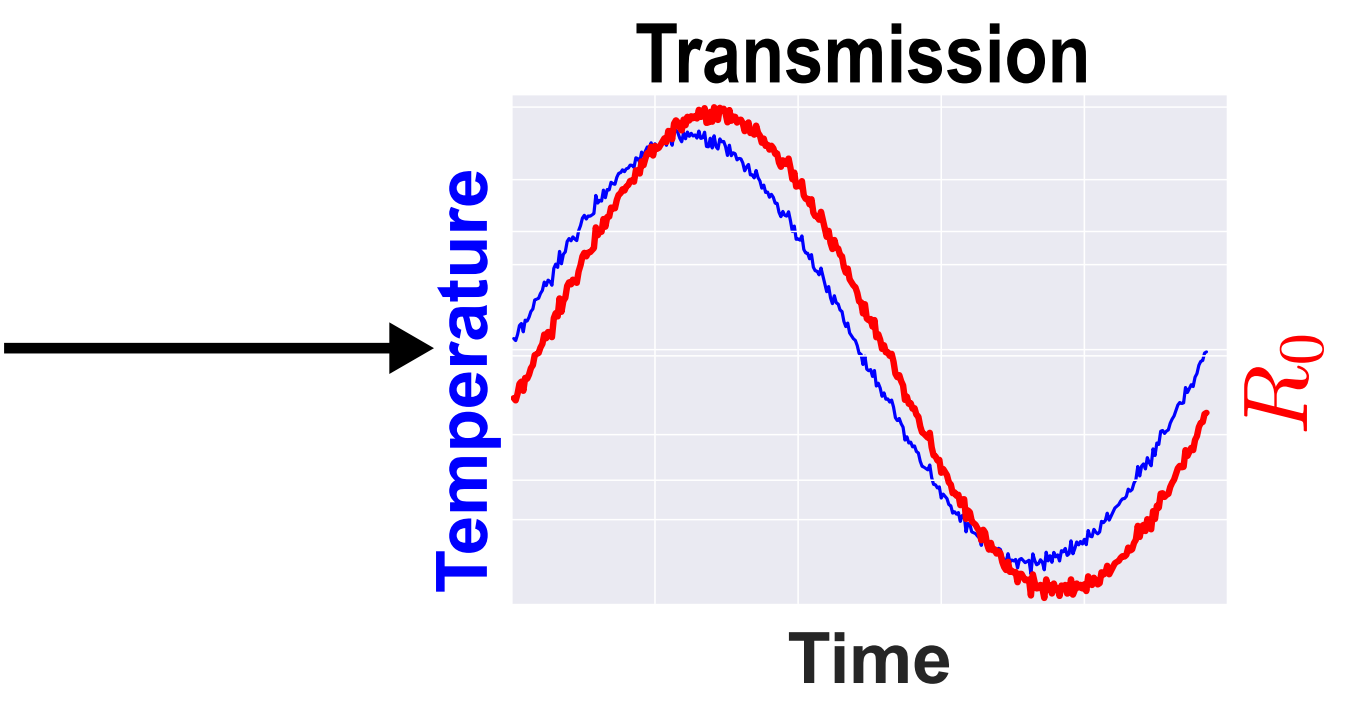

\section{Trait- based}

\section{variation}

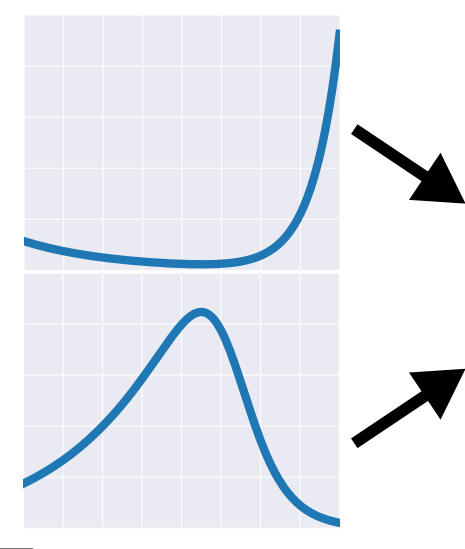

Temperature
Abundance

Fitness

Temperature

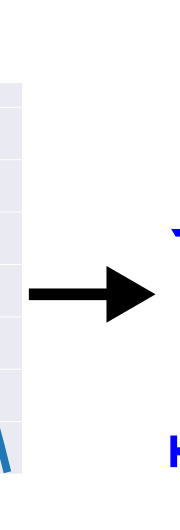

Transmission

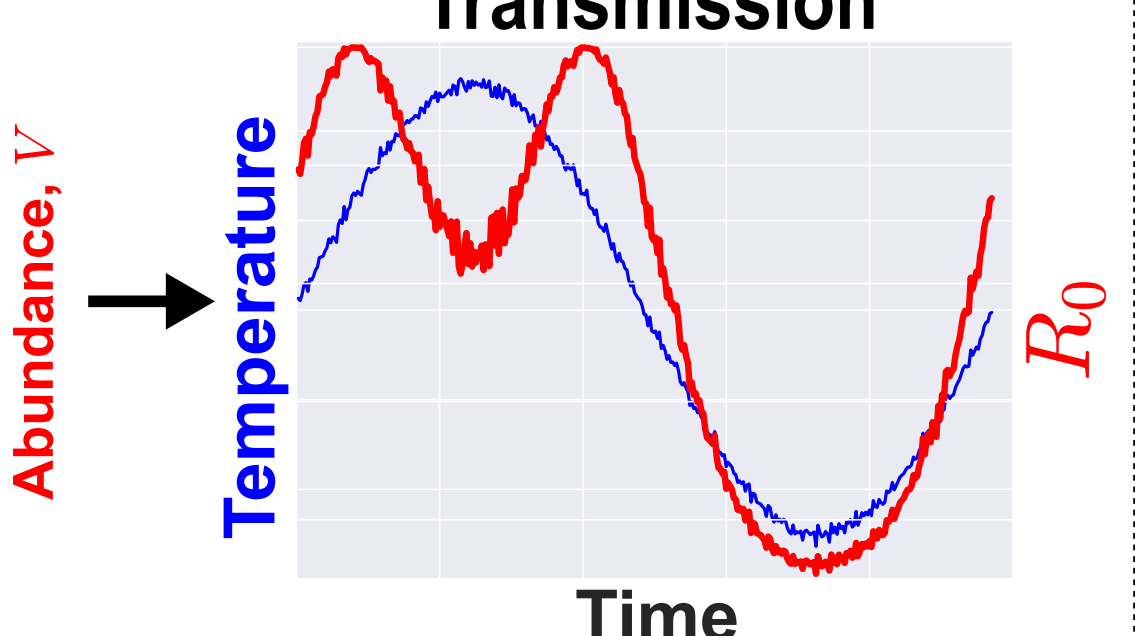




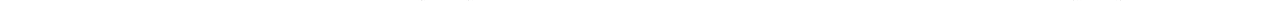



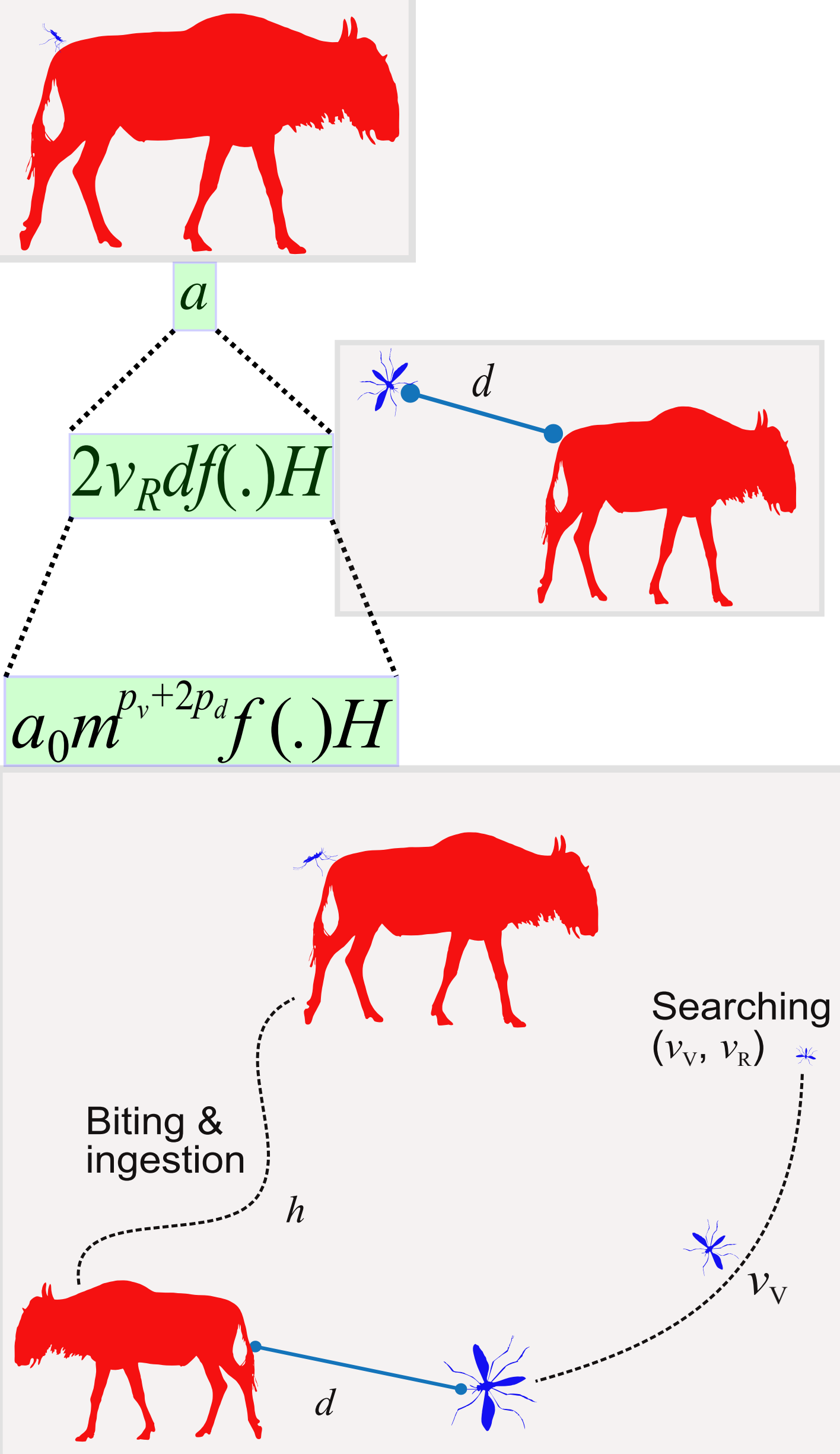
